\title{
Postsurgical Pantoea calida meningitis: a case report
}

\author{
Shirley Fritz ${ }^{1}$, Nadim Cassir $^{2}$, Remy Noudel ${ }^{3}$, Silvestre De La Rosa ${ }^{3}$, Pierre-Hugues Roche ${ }^{3}$ and Michel Drancourt ${ }^{1,4^{*}}$
}

\begin{abstract}
Introduction: Pantoea calida, a recently described environmental Enterobacteriaceae organism, has not yet been associated with human infection.

Case presentation: We report a case of postoperative meningitis caused by $P$. calida. After pituitary adenoma resection, a 52-year-old Caucasian woman developed febrile meningitis confirmed by cerebrospinal fluid analysis. $P$. calida was grown in pure culture from this fluid and was firmly identified with partial rpoB gene sequencing. She was cured by a 14-day course of meropenem.

Conclusions: $P$. calida must be added to the list of opportunistic Enterobacteriaceae pathogens responsible for postsurgical meningitis. It is easily identified by matrix-assisted laser desorption/ionization time-of-flight mass spectrometry.
\end{abstract}

Keywords: Health-care associated infection, Meningitis, Neurosurgery, Pantoea calida

\section{Introduction}

Pantoea calida has been recently described as a species of Enterobacteriaceae after its seminal isolation and culture from powdered infant formula [1]. It has not yet been associated with any infections and no clinical isolate has been reported. Here, we isolated one strain of $P$. calida from a cerebrospinal fluid (CSF) specimen and identified it as the cause of postsurgical meningitis.

\section{Case presentation}

A 52-year-old Caucasian woman had a medical history of hypertension, smoking and alcoholism. She presented with binocular diplopia. A computed tomography scan showed an intrasellar lesion with invasion of her right cavernous sinus that was further confirmed by brain magnetic resonance imaging. An endoscopic endonasal biopsy was performed and histopathology showed a nonspecific inflammation and subacute hemorrhagic alteration of her nasal mucosa. An antibiotic prophylaxis with cefazolin $2 \mathrm{gr}$ was given. A transnasal surgical excision was performed,

\footnotetext{
* Correspondence: michel.drancourt@univ-amu.fr

1URMITE, UMR63 CNRS 7278, IRD 198, Inserm 1095, Aix Marseille Université, 13005 Marseille, France

${ }^{4}$ Faculté de Médecine, Unité de recherche sur les maladies infectieuses et tropicales émergentes, 27, Boulevard Jean Moulin, Marseille Cedex 5, France Full list of author information is available at the end of the article
}

and no leak of CSF was observed after the surgery. Histopathology confirmed a single prolactin pituitary adenoma. Five days after the surgery, she presented a fever $\left(38.6^{\circ} \mathrm{C}\right)$ and a meningeal syndrome with consciousness disorder, neck stiffness and a Glasgow Coma Scale evaluated at 13 (E4V4M5) but without focal neurological deficits. The CSF collected by lumbar puncture showed hypoglycorrhachia $(1.33 \mathrm{mmol} / \mathrm{L} ; \mathrm{CSF} /$ serum glucose ratio=0.20), an elevated protein level $(5.88 \mathrm{~g} / \mathrm{L})$ and 4500 leukocytes $/ \mathrm{mL}$ including $98 \%$ polymorphonuclear leukocytes. There was no detectable organism on direct microscopic examination after Gram staining. Treatment combining intravenous vancomycin $1 \mathrm{gr}$ twice a day and intravenous meropenem $2 \mathrm{gr}$ three times a day was started for presumptive postsurgical meningitis. Her clinical condition rapidly improved, with apyrexia and a net regression of the meningeal syndrome within 2 days. Five days after the onset of symptoms, vancomycin was stopped and meropenem $6 \mathrm{gr}$ per day was continued for a total of 14 days. At 90-day follow-up she was afebrile, healthy and without any sign of meningitis.

The CSF was inoculated on Polyvitex (bioMérieux, La Balme-les-Grottes, France) and Columbia agar with 5\% sheep blood and incubated at $37^{\circ} \mathrm{C}$ under a $5 \%$ carbon dioxide atmosphere. After 48-hour incubation, small whitish round shiny domed colonies were observed on both 
culture media. Matrix-assisted laser desorption/ionization time-of-flight mass spectrometry (MALDI-TOF-MS) performed as previously described $[2,3]$ yielded $P$. calida with identification score of 2.26, 2.17 and 2.17 for the three spots deposited on the MALDI-TOF-MS plate. Furthermore partial $r р о B$ gene sequencing performed as previously reported [4] confirmed the identification of $P$. calida with $99.88 \%$ sequence similarity with the reference sequence (GenBank GQ892191). Antimicrobial susceptibility was performed by diffusion method in agar and incubated aerobically for 24 hours at $37^{\circ} \mathrm{C}$. The isolate was resistant to ampicillin (minimal inhibitory concentration (MIC) $>8 \mathrm{mg} / \mathrm{L}$ ), amoxicillin-clavulanate (MIC, $1 \mathrm{mg} / \mathrm{L}$ ), and cephalothin $(\mathrm{MIC}, 1 \mathrm{mg} / \mathrm{L})$. It was susceptible to ceftriaxone (MIC, $0.5 \mathrm{mg} / \mathrm{L}$ ), imipenem ( $\mathrm{MIC}, 0.5 \mathrm{mg} / \mathrm{L}$ ), ciprofloxacin (MIC, $0.25 \mathrm{mg} / \mathrm{L})$, gentamicin $(\mathrm{MIC}<1 \mathrm{mg} / \mathrm{L})$ and co-trimoxazole $(\mathrm{MIC}<1 \mathrm{mg} / \mathrm{L})$.

\section{Discussion}

Here, $P$. calida was isolated from the CSF of a patient with postoperative meningitis [5]. The isolate was firmly identified by using two different complementary approaches: MALDI-TOF-MS which is an advanced proteomics method [2,3] relying on the analysis of unique peptidic signatures; and partial rpoB gene sequencing which relies on the analysis of unique nucleotidic signatures [6]. These two technical approaches yielded unambiguous, concordant identification. In particular, MALDI-TOF-MS proved to be efficient to identify this species, despite the fact that no clinical isolate was previously included in the database.

The absence of any bacteria other than P. calida on the culture of CSF, as well as the fact that it was the first identification of this microorganism in our laboratory, secure the conclusion that $P$. calida was responsible for this postoperative meningitis. Accordingly, the patient was rapidly cured after an effective antibiotic treatment was administrated. In this case, the source of infection remained unknown. Indeed, $P$. calida has been documented only in powdered infant formula [1] and our patient had no contact with such formula. Of interest, the Cronobacter species (formerly Enterobacter sakazakii) causing health-care-associated meningitis in neonates [7] is also contaminating powdered infant formula $[8,9]$.

Indeed, $P$. calida is closely related to members of the Enterobacteriaceae genus Erwinia, Tatumella, Kluyvera, Citrobacter and Cronobacter, which also comprise opportunistic pathogens causing meningitis, mainly in newborns [1]. Whereas Erwinia and Tatumella organisms have not been associated with central nervous system infection, Kluyvera meningitis has been reported in a newborn [10]. Also Citrobacter bacteria are opportunistic pathogens seldom reported as causing meningitis in neonates [11], children [12] and adults with cancer [13]. Recently, one case of Citrobacter koseri meningitis has been reported after free-diving [14]. Lastly, Cronobacter species along with Enterobacter species have been reported as causes of health-care-associated meningitis [15].

\section{Conclusions}

P. calida should be added to the list of Enterobacteriaceae pathogens responsible for infectious postoperative meningitis. Sources different from powdered infant formula should be investigated. $P$. calida meningitis can be cured by appropriate antibiotic treatment. This new pathogen can easily be identified by using MALDI-TOF-MS [2,3].

\section{Consent}

Written informed consent was obtained from the patient for publication of this case report and accompanying images. A copy of the written consent is available for review by the Editor-in-Chief of this journal.

\section{Abbreviations}

CSF: Cerebrospinal fluid; MALDI-TOF-MS: Matrix-assisted laser desorption/ ionization time-of-flight mass spectrometry; MIC: Minimal inhibitory concentration.

\section{Competing interests}

The authors declare that they have no competing interests.

\section{Authors' contributions}

NC, RN, SDLR, and PHR took care of the patient. SF and MD took care of the microbiology of the specimens. SF, NC, RN, and SDLR wrote the case. PHR and $\mathrm{MD}$ evaluated the draft and suggested revisions. All authors read and approved the final manuscript.

\section{Acknowledgements}

This work was supported by URMITE, Marseille, France.

\section{Author details}

'URMITE, UMR63 CNRS 7278, IRD 198, Inserm 1095, Aix Marseille Université, 13005 Marseille, France. ${ }^{2}$ Service des Maladies Infectieuses et Tropicales, Hôpital Nord, Assistance Publique - Hôpitaux de Marseille, Chemin des Bourrely, 13915 Marseille Cedex 20, France. ${ }^{3}$ Service de Neurochirurgie, Hôpital Nord, Assistance Publique - Hôpitaux de Marseille, Chemin des Bourrely, 13915 Marseille Cedex 20, France. ${ }^{4}$ Faculté de Médecine, Unité de recherche sur les maladies infectieuses et tropicales émergentes, 27, Boulevard Jean Moulin, Marseille Cedex 5, France.

Received: 31 December 2013 Accepted: 21 April 2014

Published: 16 June 2014

\section{References}

1. Popp A, Cleenwerck I, Iversen C, De Vos P, Stephan R: Pantoea gaviniae sp. nov. and Pantoea calida sp. nov., isolated from infant formula and an infant formula production environment. Int J Syst Evol Microbiol 2010, 60:2786-2792

2. Seng P, Drancourt M, Gouriet F, La Scola B, Fournier PE, Rolain JM, Raoult D: Ongoing revolution in bacteriology: routine identification of bacteria by matrix-assisted laser desorption ionization time-of-flight mass spectrometry. Clin Infect Dis 2009, 49:543-551.

3. Seng P, Abat C, Rolain JM, Colson P, Lagier JC, Gouriet F, Fournier PE, Drancourt M, La Scola B, Raoult D: Identification of rare pathogenic bacteria in a clinical microbiology laboratory: impact of matrix-assisted laser desorption ionization-time of flight mass spectrometry. J Clin Microbiol 2013, 51:2182-2194

4. Mollet $C$, Drancourt M, Raoult D: $r p o B$ sequence analysis as a novel basis for bacterial identification. Mol Microbiol 1997, 26:1005-1011. 
5. Tavares WM, Machado AG, Matushita H, Plese JP: CSF markers for diagnosis of bacterial meningitis in postoperative neurosurgical patients. Arq Neuropsiquiatr 2006, 64:592-595.

6. Adékambi T, Drancourt M, Raoult D: The rpoB gene as a tool for clinical microbiologists. Trends Microbiol 2009, 17:37-45.

7. Hunter CJ, Bean JF: Cronobacter: an emerging opportunistic pathogen associated with neonatal meningitis, sepsis and necrotizing enterocolitis. J Perinatol 2013, 33:581-585.

8. Cai XQ, Yu HQ, Ruan ZX, Yang LL, Bai JS, Qiu DY, Jian ZH, Xiao YQ, Yang JY, Le TH, Zhu XQ: Rapid detection and simultaneous genotyping of Cronobacter spp. (formerly Enterobacter sakazakii) in powdered infant formula using real-time PCR and high resolution melting (HRM) analysis. PLoS One 2013, 8(6):e67082.

9. Yan QQ, Condell O, Power K, Butler F, Tall BD, Fanning S: Cronobacter species (formerly known as Enterobacter sakazakii) in powdered infant formula: a review of our current understanding of the biology of this bacterium. J Appl Microbiol 2012, 113:1-15.

10. Rosso M, Rojas P, Garcia E, Marquez J, Losada A, Munoz M: Kluyvera meningitis in a newborn. Pediatr Infect Dis J 2007, 26:1070-1071.

11. Cuadros EN, Castilla CY, Algarra CM, Pérez DM, Lopez BR, Martin FJ, Cardona AU: Medical and neurosurgical management of Citrobacter koseri, a rare cause of neonatal meningitis. J Med Microbiol 2014, 63:144-147.

12. Prais D, Nussinovitch M, Harel L, Amir J: Citrobacter koseri (diversus) meningitis in an otherwise healthy adolescent. Scand J Infect Dis 2003, 35:202-204

13. Tan CK, Lai CC, Lin SH, Liao CH, Huang YT, Hsueh PR: Fatal Citrobacter farmeri meningitis in a patient with nasopharyngeal cancer. J Clin Microbiol 2010, 48:1499-1500.

14. Pollara G, Savy L, Cropley I, Hopkins S: Citrobacter koseri meningitis: another freediving risk? J Infect 2011, 62:101-103.

15. Kuo CC, Wang JY, Chien JY, Chen YF, Wu VC, Tsai CW, Hwang JJ: Nontraumatic pneumocephalus due to nosocomial Enterobacter cloacae infection. Diagn Microbiol Infect Dis 2010, 66:108-110

doi:10.1186/1752-1947-8-195

Cite this article as: Fritz et al:: Postsurgical Pantoea calida meningitis: a case report. Journal of Medical Case Reports 2014 8:195.

\section{Submit your next manuscript to BioMed Central and take full advantage of:}

- Convenient online submission

- Thorough peer review

- No space constraints or color figure charges

- Immediate publication on acceptance

- Inclusion in PubMed, CAS, Scopus and Google Scholar

- Research which is freely available for redistribution 